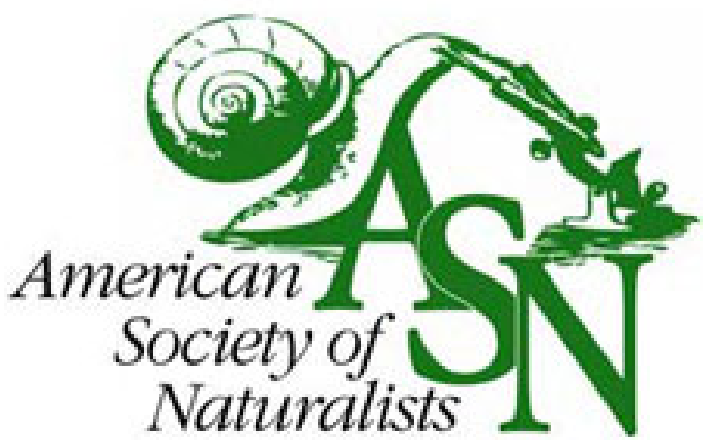

The University of Chicago

Polygenic Variation and Stabilizing Selection in a Wild Population of Lesser Snow Geese (Anser caerulescens caerulescens)

Author(s): Fred Cooke and C. Scott Findlay

Reviewed work(s):

Source: The American Naturalist, Vol. 120, No. 4 (Oct., 1982), pp. 543-547

Published by: The University of Chicago Press for The American Society of Naturalists

Stable URL: http://www.jstor.org/stable/2461077

Accessed: $21 / 06 / 2012$ 12:44

Your use of the JSTOR archive indicates your acceptance of the Terms \& Conditions of Use, available at http://www.jstor.org/page/info/about/policies/terms.jsp

JSTOR is a not-for-profit service that helps scholars, researchers, and students discover, use, and build upon a wide range of content in a trusted digital archive. We use information technology and tools to increase productivity and facilitate new forms of scholarship. For more information about JSTOR, please contact support@jstor.org. 


\section{POLYGENIC VARIATION AND STABILIZING SELECTION IN A WILD POPULATION OF LESSER SNOW GEESE (ANSER CAERULESCENS CAERULESCENS)}

Polygenic characters are generally thought to be under selection for an intermediate optimum phenotype (e.g., Lerner 1954; Lack 1966; Lande 1976). Since stabilizing selection tends to eliminate genetic variability (Wright 1935; Bulmer 1976,1980 ), and since the rate of change in the mean fitness of a population is proportional to the additive genetic variance in fitness (Fisher 1930), most quantitative characters, particularly those with large effects on fitness, should exhibit little additive variance at equilibrium. As such, the large amounts of genetic variation present in natural populations (e.g., Lewontin 1974; Nevo 1978) contrast sharply with theoretical expectations.

A plethora of mathematical models has been developed to explain the persistence of adaptive genetic variation. Theoretically, variability can be maintained by mutation (Kimura 1965; Lande 1976), frequency-dependent selection (Slatkin 1979; Bulmer 1980), selection in heterogeneous environments (Levene 1953; Haldane and Jayakar 1963; Prout 1968; Ewing 1979), or migration (Bulmer 1971; Felsenstein 1976; Slatkin 1978). Unfortunately, the generation of these models has far outdistanced their application. In this paper, we use a migration model to explain the persistence of additive variation for a polygenic trait in a colony of lesser snow geese (Anser caerulescens caerulescens) at La Pérouse Bay, Manitoba.

The results of our analysis have been reported elsewhere (Findlay and Cooke $1982 a, 1982 b$ ), and are briefly summarized below. We examined phenotypic variation in the date, relative to the population mean, at which a female's eggs hatched ("relative hatch date"). Regression analysis indicated that about $44 \% \pm 16 \%$ (1 SE) of the population variance in relative hatch date arose from a source of variation common to mothers and daughters. Although not directly testable, genotype-environment correlations are expected to contribute only marginally to the regression (Findlay and Cooke 1982a); hence, the observed heritability is a reasonable estimate of the relative amount of additive variance of the trait.

The relation between reproductive success and hatch date at the La Pérouse colony is shown in figure 1 . Reproductive success was estimated as the mean $( \pm 1$ SE) number of goslings a female successfully raised to the fledgling stage (see Findlay and Cooke 1982b). These averages are also expressed as proportions of the value obtained for the relative hatch date with the greatest mean reproductive success ("relative reproductive success"). Figure 1 is strong evidence of stabilizing selection. The greatest reproductive success accrues to those females whose clutches hatched on or near the colony mean (i.e., hatching synchronously). Assuming approximate normality, a crude estimate of the intensity of selection is given by the variance of the fitness function relative to the phenotypic variance of

Am. Nat. 1982. Vol. 120, pp. 543-547.

(C) 1982 by The University of Chicago. 0003-0147/82/2004-0009\$02.00. All rights reserved. 


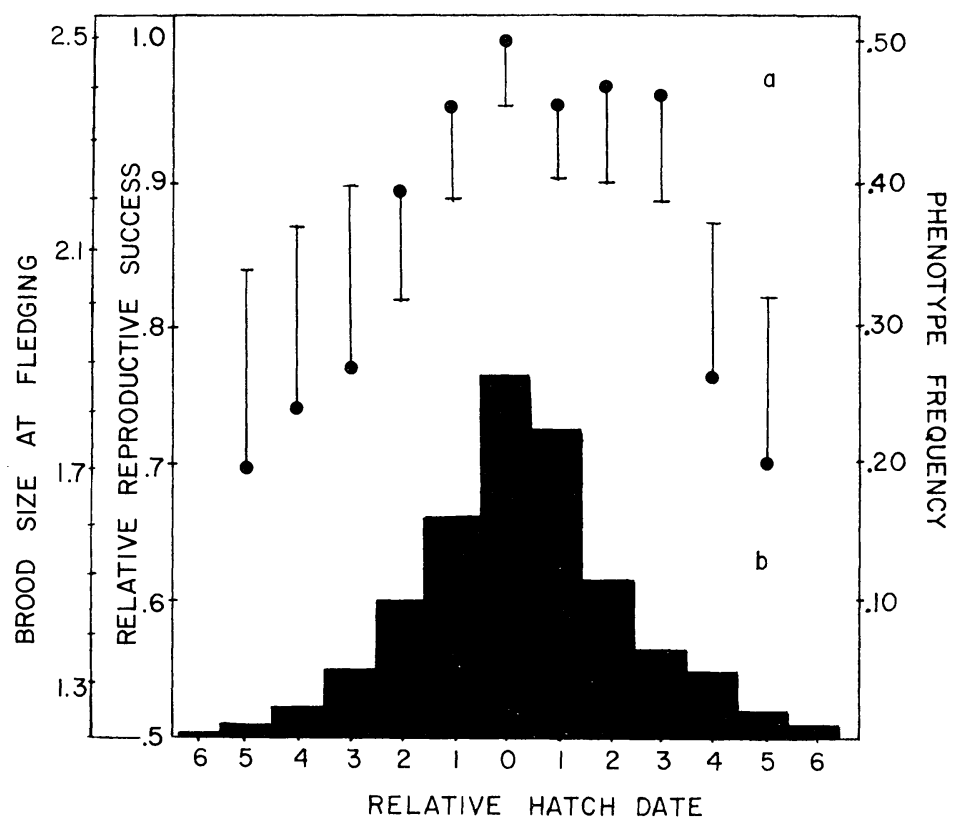

FIG. 1.- $a$, The relation between reproductive success and relative hatch date. Mean relative reproductive success ( $\pm 1 \mathrm{SE}$ ) estimates are derived from a sample of individuals of identical hatch date phenotypes (see Findlay and Cooke 1982b). $b$, Phenotype frequencies.

the trait (Roughgarden 1979). Comparison of curve $a$ with the associated phenotype frequency histogram $b$ indicates moderate selection for an intermediate optimum phenotype. The observed relationship between relative hatch date and reproductive success reflects the culmination of at least two discrete selective functions; one influencing the timing, the other the synchronization, of hatch. Curve $a$ shows that synchronized hatching is of considerable adaptive value at the La Pérouse colony. Both pre- and post-peak hatchers suffer reduced reproductive success, mainly because of increased predation rates (Findlay and Cooke 1982b).

Given that selection tends to favor intermediate hatch date phenotypes, we would expect to find low levels of heritable variation for the trait in the population. Why then does a significant additive component still exist?

It is possible that the estimated heritability simply measures transient genetic variation. The recent climatic amelioration of the eastern arctic has exposed snow geese populations to new environmental conditions, altering gene frequencies for at least one known trait (Cooch 1961, 1963). If the population is not at equilibrium, we might expect a reduction in the additive variance as the population evolves toward a new phenotypic optimum (Bulmer 1980).

Alternatively, our estimate may measure the amount of additive variance maintained in the population. In this context, we suggest that immigration plays a crucial role in the maintenance of genetic variability. Snow geese breed in geographically isolated colonies (segments) throughout the Canadian arctic. Pair formation occurs on the wintering grounds or during spring migration, where there 
is considerable intermixing of individuals from different segments. Hence, pairs often comprise birds of different geographical origin. The tendency of pairs to return to the female's natal colony to breed (Cooke et al. 1975), results in a large influx of nonnatal males into each segment every generation. At the smaller colonies, including La Pérouse Bay, immigration rates approach $50 \%$ per generation (Rockwell and Cooke 1977).

While such massive gene flow probably precludes permanent local adaptation of the gene pool, gene frequencies may undergo temporary geographical differentiation in response to varying selection functions, effectively reducing the genetic correlation between segments at the time of pair formation. The equilibrium additive variance of a polygenic trait in an open population is, in part, determined by the migration rate $m$, and the difference between the optimal phenotypic values in the donor and recipient demes $\left(\theta_{d}-\theta_{r}\right.$; Bulmer 1980). Since at the La Pérouse Bay colony $m \cong 0.5$, immigration may have a large effect on the equilibrium additive variance of relative hatch date (Slatkin 1978), provided the trait is autosomally inherited.

If the relative reproductive success of a particular hatch date phenotype is determined solely by its synchronization (with other phenotypes), then stabilizing selection will act only to reduce the variance around the mean, and indeed, is independent of the mean's absolute value. This implies that where donor and recipient demes differ in their optimal phenotypic values, these values are set by some selection pressure other than for synchronization.

Other factors are important in determining hatch date variability, particularly at other colonies. Adverse weather conditions in the early fall occur regularly at higher latitudes and have been shown to result in the death of the goslings of late-hatching families (Barry 1962). Under such conditions, pre-peak females, while presumably suffering by hatching asynchronously, nonetheless ensure a sufficient period for gosling development prior to migration. This interval is reduced as the hatch period progresses. The more robust goslings from earlyhatching clutches are more likely to survive the southward migration, and will contribute proportionately more to the breeding population of the next generation. Here, phenotypic variability is exposed to the two independent selection functions cited earlier; one based on the timing, the other on the synchronization, of hatch. If the optimum values $\left(\theta_{t}, \theta_{s}\right)$ set by the timing and synchronization selection functions ( $W[t], W[s]$, respectively) differ, the resulting variance is a function of their relative selection intensities and the optimum differential $\left(\theta_{t}-\theta_{s}\right)$. Assuming a normally distributed phenotypic density function, $\theta_{t}$ is simply the population mean $(M)$; hence while $W(t)$ tends to shift $M$ toward $\theta_{t}$ by favoring early hatching phenotypes (directional selection), $W(s)$ acts to reduce the variance around $M$ (stabilizing selection). When $M=\theta_{t}$, stabilizing selection operates through both $W(s)$ and $W(t)$. Regardless of what the population's equilibrium mean $(\hat{M})$ value is, $W(s)$ will always tend to reduce the phenotypic variance of relative hatch date provided that intermediate (synchronous) phenotypes are always accrued the greatest reproductive success. Where colonies differ in $M$ because of geographical variation in $\theta_{t}, W(s)$ will act to reduce the genetic correlation between them.

Given the often large latitudinal separation of different segments of the total 
snow goose population (Dzubin et al. 1973), $\theta_{t}$ probably varies considerably between colonies. Moreover, $W(s)$ may itself show some degree of intercolony variation. In several colonies, there is evidence of a degradation of the available food resources. Here, goslings hatched from synchronous clutches compete for food with a large group of conspecifics. Asynchronous broods, however, enjoy reduced competitive pressure and may accrue a greater relative fitness. Under such conditions, density-dependent competition may lead to disruptive selection favoring asynchronous phenotypes.

Additive hatch date variation undoubtedly reflects underlying physiological variability. Genotypes may vary in their environmental response thresholds or stimulus-response lag times because of different hormonal levels. If the response in question is the initiation of egg production, this variation will translate into phenotypic variation in the time at which the clutches of particular genotypes hatch (Findlay and Cooke 1982a). The different optimum values of the donor and recipient colonies would then represent different optimal hormonal titres.

We have demonstrated a significant additive component of variance for a quantitative trait subject to stabilizing selection. These empirical results contrast with theoretical expectations under the assumptions of a closed population at genetic equilibrium. A sufficient explanation for our observations may be generated if we relax one or both of these premises. Moreover, these explanations can be expressed as empirically testable hypotheses. If the population is not at equilibrium, we predict a reduction in the additive component of variance in subsequent generations. Alternatively, the hypothesis that genetic variability is maintained through male immigration is applicable only if (1) relative hatch date is a character that is not sex-linked to females and (2) the relationship between reproductive success and relative hatch date varies from colony to colony within a season. Thus, if we estimated fitness curves for several colonies, we would expect to find some with a maximum to the left, others to the right, of the mean relative hatch date.

\section{ACKNOWLEDGMENTS}

The authors thank Robert Rockwell, Patrick Colgan, Robert Montgomerie, and two anonymous reviewers for their comments on earlier versions of this manuscript. This study represents part of a larger investigation of snow goose breeding biology funded in part by the Natural Sciences and Engineering Research Council of Canada, the Canadian Wildlife Service, the Manitoba Department of Renewable Resources, the Mississippi and Central Flyway Councils, and the World Wildlife Fund.

LITERATURE CITED

Barry, T. W. 1962. The effect of late seasons on Atlantic brant reproduction. J. Wildl. Manage. 26:19-26.

Bulmer, M. G. 1971. Stable equilibria under the migration matrix model. Heredity 27(3):419-430.

1976. The effect of selection on genetic variability: a simulation study. Genet. Res. 28:101117. 
1980. The mathematical theory of quantitative genetics. Clarendon, Oxford.

Cooch, F. G. 1961. Ecological aspects of the blue-snow complex. Auk 78:72-89.

1963. Recent changes in the distribution of color phases of Chen c. caerulescens. Proc. XIII Int. Ornithol. Congr. 1962:1182-1194.

Cooke, F., C. D. MacInnes, and J. P. Prevett. 1975. Gene flow between breeding populations of lesser snow geese. Auk 92:493-510.

Dzubin, A., H. Boyd, and W. J. D. Stephen. 1973. Blue and snow goose distribution in the Mississippi and Central flyways: a preliminary report. Vol. 1. Reprint mimeo report, Can. Wildl. Serv., Ottawa.

Ewing, E. P. 1979. Genetic variation in a heterogeneous environment VII. Temporal and spatial heterogeneity in infinite populations. Am. Nat. 114(2):197-212.

Felsenstein, J. 1976. The theoretical population genetics of variable selection and migration. Annu. Rev. Genet. 10:253-280.

Findlay, C. S., and F. Cooke. 1982a. Breeding synchrony in the lesser snow goose (Anser caerulescens caerulescens) I. Genetic and environmental components of hatch date variability and their effects on hatch synchrony. Evolution 36:342-351.

Findlay, C. S., and F. Cooke. 1982b. Synchrony in the lesser snow goose (Anser caerulescens caerulescens) II. The adaptive value of reproductive synchrony. Evolution (in press).

Fisher, R. A. 1930. The genetical theory of natural selection. Clarendon, Oxford.

Haldane, J. B. S., and S. D. Jayakar. 1963. Polymorphism due to selection of varying direction. J. Genet. 58:237-242.

Kimura, M. 1965. A stochastic model concerning the maintenance of genetic variability in quantitative characters. Proc. Natl. Acad. Sci. USA 54:731-736.

Lack, D. S. 1966. Population studies of birds. Clarendon, Oxford.

Lande, R. 1976. The maintenance of genetic variability by mutation in a polygenic character with linked loci. Genet. Res. 26:221-235.

Lerner, I. M. 1954. Genetic homeostasis. Oliver \& Boyd, Edinburgh.

Levene, H. 1953. Genetic equilibrium where more than one ecological niche is available. Am. Nat. 87:311-313.

Lewontin, R. C. 1974. The genetic basis of evolutionary change. Columbia University Press, New York.

Nevo, E. 1978. Genetic variation in natural populations: patterns and theory. Theor. Popul. Biol. 13:121-177.

Prout, T. 1968. Sufficient conditions for multiple niche polymorphism. Am. Nat. 102:493-496.

Rockwell, R. F., and F. Cooke. 1977. Gene flow and local adaptation in a colonial nesting dimorphic bird: the lesser snow goose (Anser caerulescens caerulescens). Am. Nat. 111:91-97.

Roughgarden, J. 1979. Theory of population genetics and evolutionary ecology: an introduction. Macmillan, New York.

Slatkin, M. 1978. Spatial patterns in the distribution of polygenic characters. J. Theor. Biol. 70:213228.

1979. Frequency- and density-dependent selection in a quantitative character. Genetics 93:755-771.

Wright, S. 1935. Evolution in populations in approximate equilibrium. J. Genet. 30:257-266.

\author{
Department of Biology \\ QUEEN'S UNIVERSITY \\ Kingston, Ontario, Canada K7L 3N6 \\ Submitted September 25, 1981; Revised March 15, 1982; Accepted March 18, 1982
}

